\title{
Injuries and illnesses of football players during the 2010 FIFA World Cup
}

\author{
Jiri Dvorak, ${ }^{1,2}$ Astrid Junge, ${ }^{2}$ Wayne Derman, ${ }^{3}$ Martin Schwellnus ${ }^{3}$
}

${ }^{1}$ Fédération Internationale de Football Association (FIFA), Zurich, Switzerland 2FIFA Medical Assessment and Research Centre (F-MARC) and Schulthess Clinic, Zurich, Switzerland ${ }^{3}$ UCT/MRC Research Unit for Exercise Science and Sports Medicine, Department of Human Biology, University of Cape Town, Cape Town, South Africa

\section{Correspondence to}

Dr Astrid Junge, F-MARC,

Schulthess Klinik, Lengghalde 2. CH-8008 Zurich,

Switzerland;

Medical@FIFA.org

Accepted 3 December 2010 Published Online First 21 January 2011

\section{(2) UNLOCKED}

This paper is freely available online under the BMJ Journals unlocked scheme, see http:// bjsm.bmj.com/info/unlocked.dtl
ABSTRACT

Background The incidence and characteristics of football injuries during matches in top-level international tournaments are well documented, but training injuries and illnesses during this period have rarely been studied. Aim To analyse the incidence and characteristics of injuries and illnesses incurred during the 2010 Fédération Internationale de Football Association (FIFA) World Cup. Methods The chief physicians of the 32 finalist teams reported daily all newly incurred injuries and illnesses of their players on a standardised medical report form.

Results Out of 229 injuries reported, 82 match and 58 training injuries were expected to result in time loss, equivalent to an incidence of 40.1 match and 4.4 training injuries per $1000 \mathrm{~h}$. Contact with another player was the most frequent cause of match (65\%) and of training (40\%) injuries. The most frequent diagnoses were thigh strain and ankle sprain. 99 illnesses of 89 (12\%) players were reported. Illnesses were mainly infections of the respiratory or the digestive system. Most illnesses did not result in absence from training or match. The incidence of timeloss illnesses was 3.0 per 1000 player days.

Conclusion The incidence of match injuries during the 2010 FIFA World Cup was significantly lower than in the three proceeding World Cups. This might be a result of more regard to injury prevention, less foul play and stricter refereeing. Tackling skills and fair play need to be improved to prevent contact injuries in training and matches. Prevention of illness should focus on reducing the risk of infections by considering the common modes of transmission and environmental conditions.

Injury and illness surveillance studies are an integral part in the effort to protect athletes' health..$^{1-3}$ It provides not only important information on the number, characteristics and causes of the health problems and directions for their prevention, but also the opportunity for monitoring long-term changes in their occurrence. Innovations (eg, artificial turf or new rules) and the effects of preventive interventions can thus be evaluated. The Fédération Internationale de Football Association (FIFA) started in 1998 to survey all injuries incurred during their competitions, ${ }^{1}$ and other international sports federations followed the model of FIFA Medical Assessment and Research Centre (F-MARC). ${ }^{4-8}$ Based on their experiences, an international expert group from F-MARC, the International Association of Athletics Federations (IAAF), Fédération Internationale de Natation (FINA), the International Ice Hockey Federation and the International Olympic Committee developed a surveillance system for injuries, ${ }^{9-11}$ and extended it in a second step also to include illnesses. $^{12-14}$
The incidence and characteristics of football injuries during matches in top-level international tournaments such as the Olympic Games, European Championships and World Cups are well documented, ${ }^{1-4} 7$ while training injuries and illness during the competitions have rarely been studied. ${ }^{7}$ The incidence of time-loss injuries in matches were 50.7 injuries per $1000 \mathrm{~h}$ in the 2002 FIFA World Cup, ${ }^{3} 45.9$ in the 2006 FIFA World Cup, ${ }^{2} 36.0$ in EURO $2004^{7}$ and 41.6 in EURO 2008. ${ }^{4}$ The incidence of training injuries at the European Championships varied between 0 and 3.9 time-loss injuries per 1000 training hours. ${ }^{4} 7$

In a prospective study on the illnesses of elite football players, ${ }^{15}$ the incidence was $2.5 \mathrm{com}$ plaints per player per season, and approximately $20 \%$ resulted in absence. Almost all complaints were classified as upper respiratory and gastrointestinal illnesses. ${ }^{15}$ In a pilot study during the FIFA Confederations Cup 2009, the incidence of illness was 16.5 per 1000 player days, and more than $60 \%$ were affected in the respiratory tract (Schwellnus MP, Dvorak J, Derman W, et al. Medical conditions and illnesses in elite football players during international competition: a pilot study, personal communication).

The aim of the present study is to analyse the incidence and characteristics of (match and training) injuries and illness in football players participating in the 2010 FIFA World Cup in order to direct future prevention initiatives.

\section{METHODS}

The applied methodology combined the FIFA injury reporting ${ }^{1}$ and the International Olympic Committee injury and illness surveillance ${ }^{10}$ systems to allow comparison with previous studies. The injury definition and data collection procedure were in accordance with the respective consensus statement for football injuries. ${ }^{16}$

The definition of injury was identical to the one used in previous FIFA competitions ${ }^{2}{ }^{3} 9$ but extended to training injuries. An injury was defined as 'any musculoskeletal complaint and concussion newly incurred due to competition or training during the 2010 FIFA World Cup ${ }^{\mathrm{TM}}$.'

The definition of an illness was developed based on the injury definition and had proved feasible in the 2009 FIFA Confederation Cup, the 2009 world championships of FINA and IAAF as well as during the 2010 Winter Olympics. ${ }^{12-14}$ An illness was defined as 'any physical complaint (unrelated to injury) newly incurred during the 2010 FIFA World Cup ${ }^{\mathrm{TM}^{6}}$. Chronic preexisting illnesses were 
not included unless there was an exacerbation requiring medical attention during the study period.

The medical report form was almost identical to the form that was developed for the 2009 IAAF and FINA championships, as well as the 2010 Winter Olympic games. ${ }^{12-14}$ However, the form was slightly modified to: (1) collect football-specific information on cause of injury (the coding used was in accordance with previous FIFA competitions); (2) include codes for illness using the International Statistical Classification of Diseases and Related Health Problems, 10th revision system; and (3) include the duration of the daily training.

The chief physicians of the 32 finalist teams received detailed information about the study during the medical meeting held in February 2010. As part of the preparation, written informed consent to participate in the study was obtained from all the players. Upon their arrival in South Africa, each team physician received a booklet of daily medical report forms and was requested to complete one form daily starting on the first day of the World Cup (11 June) until the team leaves the competition. The completed forms were collected by a FIFA medical officer after each match during doping control. Confidentiality of all information was ensured and no individual player or team could be identified. Ethics approval for the study was obtained from the Research Ethics Committee of the Faculty of Health Sciences, University of Cape Town (ref. no. REC 159/2009).

The 64 matches of the 2010 FIFA World Cup were played from 11 June to 11 July in 10 different venues in South Africa. The 32 participating finalist teams with 23 players each comprised a total of 736 players. The number of matches per team varied between three and seven, and thus the duration of the competition for teams varied between 12 and 31 days. In total, the study period included 13179 player days.

Response rate, exposure time and incidences were calculated in accordance with the consensus statement and previous studies. ${ }^{1} 1016$ Match exposure was calculated by multiplying $1.5 \mathrm{~h}$ by 11 players by the number of returned forms. Training exposure was calculated by multiplying the sum of the daily training times of all teams by 23 players. The number of player days was calculated by adding the number of days each team participated (starting on 11 June to the last match of the team) multiplying by 23 players. For incidence rates, 95\% CI were calculated as the incidence \pm 1.96 times the incidence divided by the square root of the number of injuries. Data were processed using Excel and SPSS. The statistical methods applied were frequencies, cross-tabulations and $\chi^{2}$ test. Significance was accepted at the $5 \%$ level.

\section{RESULTS}

\section{Response rate and exposure time}

The team physicians of all 32 finalist teams (comprising 736 players) participated in the study. In total, 553 daily medical report forms were returned, equivalent to an overall response rate of $97.4 \%$. From match days, four medical reports were missing, resulting in a response rate of $96.9 \%$ or 2046 player hours. For the other days, 429 (97.5\%) forms were returned, but on $54(12.3 \%)$ forms training hours were not reported and on six they were not legible. A total of $490.8 \mathrm{~h}$ of team training were reported (and it can be estimated that 81.4 were missing), which is equivalent to 13160 player hours training.

\section{Match injuries}

In total, 125 injuries were reported from the 64 matches, resulting in an average of 2.0 injuries per match (95\% CI 1.7 to

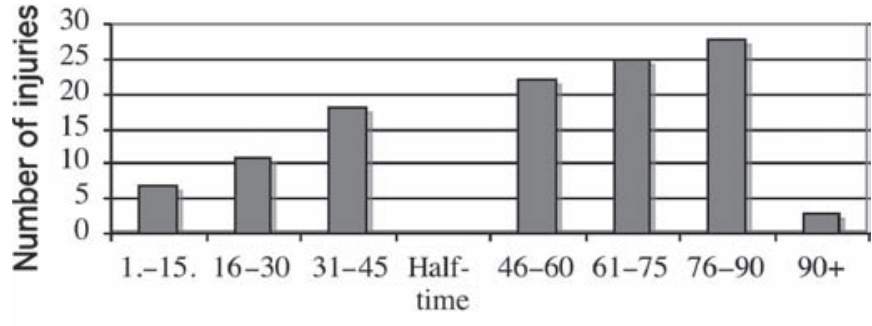

Time (min)

Figure 1 Number of injuries during the course of the match $(n=114$; for four injuries in the second half the exact minute was not specified; for seven injuries information is missing).

2.3) or 61.1 per 1000 match hours (95\% CI 50.4 to 71.8$)$. More than a third of the injuries $(35.5 \%, 44$ of 124$)$ were incurred without contact with another player and $64.5 \%$ were contact injuries. Less than a quarter $(22.5 \%)$ of contact injuries or $14.4 \%$ of all injuries were caused by foul play based on the judgement of the team physician. In the first half of the match, $36(30.5 \%)$ injuries occurred, more than twice as many $(79 ; 66.9 \%)$ in the second half and three $(2.5 \%)$ injuries during overtime/extra time (information missing for seven injuries, see figure 1).

The injuries most frequently affected the lower extremity $(92 ; 73.6 \%)$ followed by the head/neck $(13 ; 10.4 \%)$, upper extremity $(12 ; 9.6 \%)$ and the trunk $(8 ; 6.4 \%)$. The most frequent diagnoses were contusion of thigh and lower leg and thigh strain (table 1).

Approximately a third of the injuries (39; 34.8\%) did not prevent the player from training or match play. Half of the injuries $(59 ; 52.7 \%)$ resulted in absence from sport of $1-3$ days, nine injuries (8.0\%) in absence of 4-7 days, and three $(2.7 \%)$ resulted in absence of 10 days. Two fractures of the foot/ankle had an expected rehabilitation time of more than a month. For nine injuries, time loss was expected but the duration was not specified. For four injuries (two ankle sprains, one medial collateral ligament sprain and an unspecified shoulder injury) no information on time loss was provided. On average, 1.3 time-loss injuries per match $(95 \% \mathrm{CI}$ 1.0 to 1.6 ) or 40.1 per 100 match hours ( $95 \%$ CI 31.4 to 48.8 ) were reported.

\section{Training injuries}

A total of 104 injuries was incurred during training sessions, equivalent to 7.9 per 1000 player hours (95\% CI 6.4 to 9.4). The cause of injury was classified as overuse in 25 (24.0\%) cases, as recurrence of a previous injury in $12(11.5 \%)$ cases and as non-contact trauma in $24(23.1 \%)$ cases. Forty-two injuries (40.4\%) were caused by contact with another player (including 12 injuries caused by foul play), and one injury was attributed to contact with the ball. The most frequent diagnoses were ankle sprain and thigh strain (table 1).

Approximately half $(58 ; 57.4 \%)$ of the injuries were expected to result in absence from training or match (no information regarding time loss was provided for three injuries). The duration of absence was estimated to be 1-3 days for $44(43.6 \%)$ injuries, 4-7 days for five (5.0\%) injuries and more than a week but less than a month for six (5.9\%) injuries. A thigh strain was expected to result in time loss of a month. For two thigh sprains the duration of time loss was not specified. The incidence of time-loss training injuries was 4.4 per 1000 training hours (95\% CI 3.3 to 5.5$)$. 
Table 1 Location and diagnosis of match and training injuries $(\mathrm{n}=229)$

\begin{tabular}{|c|c|c|c|c|}
\hline \multirow[b]{2}{*}{ Location and diagnosis } & \multicolumn{2}{|c|}{ Match injuries } & \multicolumn{2}{|c|}{ Training injuries } \\
\hline & All & With absence & All & With absence \\
\hline Head/neck & 13 & 4 & 6 & 3 \\
\hline Concussion & 1 & 1 & 1 & 0 \\
\hline Fracture of os nasalis & 1 & 1 & 0 & 0 \\
\hline Contusion & 4 & 1 & 2 & 0 \\
\hline Laceration & 6 & 0 & 1 & 1 \\
\hline Dental fracture & 1 & 1 & 0 & 0 \\
\hline Muscle cramps (neck) & 0 & 0 & 2 & 2 \\
\hline Upper extremity & 12 & 6 & 4 & 2 \\
\hline Fracture & 1 & 0 & 0 & 0 \\
\hline Sprain & 4 & 3 & 0 & 0 \\
\hline Contusion & 4 & 3 & 1 & 0 \\
\hline Laceration & 0 & 0 & 1 & 0 \\
\hline Arthritis & 2 & 0 & 0 & 0 \\
\hline Others/not specified & 1 & * & 2 & 2 \\
\hline Trunk & 8 & 5 & 10 & 4 \\
\hline Contusion & 5 & 2 & 3 & 0 \\
\hline Sprain/strain & 2 & 2 & 1 & 1 \\
\hline Others & 1 & 1 & 6 & $3^{*}$ \\
\hline Hip & 2 & 1 & 1 & 1 \\
\hline Contusion & 1 & 0 & 0 & 0 \\
\hline Tendinosis/tendinopathy & 1 & 1 & 0 & 0 \\
\hline Impingement & 0 & 0 & 1 & 1 \\
\hline Groin & 4 & 4 & 3 & 3 \\
\hline Muscle strain & 3 & 3 & 1 & 1 \\
\hline Tendonitis & 1 & 1 & 1 & 1 \\
\hline Muscle cramps & 0 & 0 & 1 & 1 \\
\hline Thigh & 36 & 25 & 19 & 13 \\
\hline Muscle strain/rupture & 11 & 10 & 11 & 9 \\
\hline Contusion & 12 & 6 & 2 & 1 \\
\hline Muscle cramps/tightness & 9 & 7 & 3 & 2 \\
\hline Laceration & 0 & 0 & 1 & 0 \\
\hline Others & 4 & 2 & 2 & 1 \\
\hline Knee & 9 & 6 & 16 & 9 \\
\hline Sprain & 4 & 3 & 3 & 3 \\
\hline Tendinosis/tendinopathy & 0 & 0 & 2 & 1 \\
\hline Arthritis & 0 & 0 & 4 & 3 \\
\hline Contusion & 3 & 1 & 4 & 1 \\
\hline Laceration & 2 & 2 & 0 & 0 \\
\hline Others & 0 & 0 & 3 & 1 \\
\hline Lower leg & 19 & 12 & 18 & 9 \\
\hline Muscle strain/rupture & 6 & 5 & 2 & 1 \\
\hline Contusion & 11 & 5 & 9 & 2 \\
\hline Laceration, abrasion & 0 & 0 & 3 & 3 \\
\hline Muscle cramps & 0 & 0 & 2 & 2 \\
\hline Others & 2 & 2 & 2 & 1 \\
\hline Ankle & 15 & 12 & 17 & 8 \\
\hline Fracture and sprain & 1 & 1 & 0 & 0 \\
\hline Ligament rupture & 1 & 1 & 0 & 0 \\
\hline Sprain & 6 & $4^{*}$ & 12 & $8^{*}$ \\
\hline Contusion & 7 & 6 & 5 & $0^{*}$ \\
\hline Foot & 7 & 7 & 10 & 6 \\
\hline Fracture & 1 & 1 & 0 & 0 \\
\hline Contusion & 6 & 6 & 6 & 3 \\
\hline Abrasion & 0 & 0 & 1 & 1 \\
\hline Others & 0 & 0 & 3 & 2 \\
\hline
\end{tabular}

*Information was missing for at least one injury.

\section{Illnesses}

Ninety-nine illnesses were reported in 89 players $(12.1 \%$ of all players) and this was equivalent to 135 per 1000 players or 7.7 per 1000 player days (95\% CI 6.2 to 9.2 ). The majority of illnesses affected either the respiratory $(40 ; 40.4 \%)$ or the digestive $(26 ; 26.3 \%)$ system. The most frequent diagnoses were acute upper respiratory tract infection $(31 ; 31.3 \%)$ and gastroenteritis $(21 ; 21.2 \%)$ followed by sleep disorders (10; $10.1 \%)$. In half of the cases $(50 ; 50.5 \%)$, the main symptom was pain either solely $(35 ; 35.4 \%)$ or in combination with fever (five), diarrhoea/vomiting (five) dyspnoea/cough (three) or other symptoms (two). A total of 14 (14.1\%) illnesses was associated with fever. The cause of most illnesses was either infection $(60 ; 60.6 \%)$ or environmental $(23 ; 23.2 \%)$. Other causes of illness were rare (exercise-induced (four), pre-existing sleep disorder (two), others (nine), not specified (one)). The most common treatments were antibiotics (37; $37.4 \%)$ either as monotherapy $(14 ; 14.1 \%)$ or in combination with other drugs $(22 ; 22.2 \%)$, and oral analgesics $(24 ; 24.2 \%)$ either as monotherapy (seven; $7.1 \%$ ) or in combination (17; $17.2 \%)$. Non-steroidal anti-inflammatory drugs $(9.1 \%)$ were given for four infections of the respiratory system, three dental problems and two other illnesses. In the majority of cases $(63 ; 63.6 \%)$ a single treatment was prescribed, the most frequent combination $(10 ; 10.1 \%)$ was antibiotics and oral analgesics. More than half $(55 ; 59.1 \%)$ of the illnesses did not result in absence from training or match, and $36(38.7 \%)$ in absence of 1-3 days. For six illnesses time loss was not specified. The most severe illnesses were urethritis/nephritis and an infected anal fistula, both were expected to cause 5 days of absence from sport. The incidence of time-loss illnesses was 3.0 per 1000 player days (95\% CI 2.0 to 4.0 ), and the expected duration of a time-loss illness was on average 1.76 days (SD 0.94).

\section{DISCUSSION}

Starting at the World Cup 1998, F-MARC has surveyed match injuries in all 44 subsequent FIFA competitions. ${ }^{1}$ Thanks to the team physicians' excellent compliance, a high response rate and good quality data were obtained..$^{1-3}$ This database enables comparison between competitions for different age, gender and skill levels and over time. Other sports federations adapted the F-MARC injury surveillance system for their sports, so that injury and illness data can now also be compared between different sports. 569101214

The incidence of match injuries during the 2010 FIFA World Cup was significantly lower than the average of the three previous World Cups (2.4; 95\% CI 2.2 to 2.6$),{ }^{1-3}$ and also the incidence of time-loss injuries was lower than in any of those competitions (figure 2). In general, the location and type of injuries was similar to the previous World Cups, but a tendency of less knee and more thigh injuries was observed. ${ }^{1-3}$ However, the cause of injury differed substantially from the previous World Cups, with more injuries caused without contact (2010: 36\%; 2002 and 2006: 27\%). ${ }^{2}{ }^{3}$ This might be due to the overload of the players with too many matches, as discussed previously. ${ }^{17}$ This theory is further supported by the observation that in the recent World Cup not only was a higher proportion of injuries incurred in the second half than in previous World Cups (2010: 69\%; 1998-2006: 50-54\%) but also the number of injuries increased progressively during the course of the match (figure 1). ${ }^{1-3}$ In the 2010 FIFA World Cup only $23 \%$ of the contact injuries were caused by foul 
play based on the judgement of the team physician. This percentage is substantially lower than in $2006(61 \%)^{2}$ and 2002 $(51 \%){ }^{3}$ This result, however, should be interpreted with caution because the documentation of injury cause was different in 2010 than in the previous competitions. Therefore, this aspect should be evaluated further using video analysis of the injury situations.

The evidence of decreasing injury incidence during FIFA World Cups since 1998 is the contribution of medicine and science to 'development of the game', a key objective of FIFA and an important factor for the future promotion of football as a health-enhancing leisure activity. Based upon the data it can be assumed that a further reduction of injuries could be reached by appropriate preparation for the competition, including the F-MARC prevention programme the $11+,{ }^{18}$ strict application of the laws of the game by referees, and finally by changing attitudes towards 'fair play' by the coaches and players.

Training injuries differed substantially from match injuries with respect to diagnosis (table 1) and cause, but not in severity. While it could be expected that training injuries were more often as a result of overuse and non-contact trauma than match injuries, it was interesting to note that 12 training injuries were reported to be caused by foul play. Six of these injuries were reported from one team. The incidence of time-loss training injuries was similar to those at the European Championships (1.3-3.9 per 1000 training hours). ${ }^{4}$

An illness was reported in $12 \%$ of the players during the period of the 2010 FIFA World Cup. At the 2009 FINA World Championships (aquatics) ${ }^{14} 7.1 \%$ of the registered athletes, at the 2009 IAAF World Championships in athletics ${ }^{12} 6.7 \%$, and at the 2010 Winter Olympic Games ${ }^{13} 6.7 \%$ were reported to have had an illness. These figures should, however, not be compared because of the varying duration of the championships. To compare different championships, incidences of illness should be expressed per 1000 athlete days. For the 2009 world championships in athletics, ${ }^{12}$ an illness incidence of 7.6 per 1000 athlete days could be estimated, which is similar to that in the present study. In the FIFA Confederations Cup 2009, however, the incidence of illness was 16.5 per 1000 player days (Schwellnus MP, Dvorak J, Derman W, et al. Medical conditions and illnesses in elite football players during international competition: a pilot study, personal communication). In all quoted studies, ${ }^{12-14}$ the respiratory system was affected mostly, pain was the most frequent symptom, and infection the most frequent cause, as also observed during the 2010 FIFA World Cup. The gastrointestinal system was the second most affected in aquatics, ${ }^{14}$ winter sports ${ }^{13}$ and football, whereas it was the cardiovascular system in athletics ${ }^{12}$ (probably due to the hot weather during that championships).

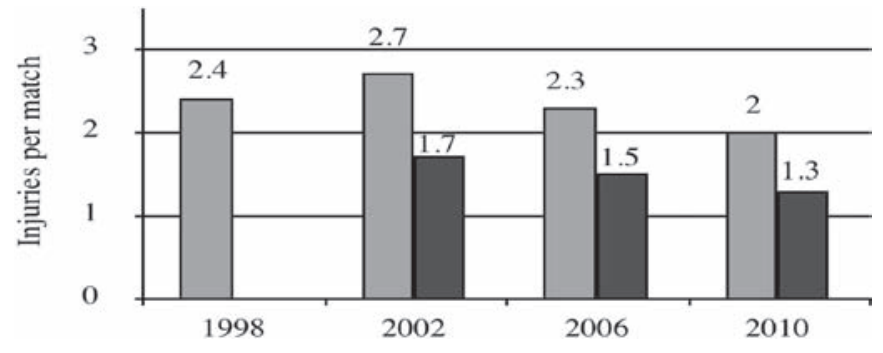

Figure 2 Average number of injuries per match in Fédération Internationale de Football Association World Cups 1998-2010 (grey: all injuries; black: time-loss injuries). ${ }^{1-3}$
At the recent football World Cup, only $4 \%$ of the illnesses were classified as exercise-induced compared with $29 \%$ at the athletic world championships in Berlin. ${ }^{12}$ The incidence and expected duration of time-loss illnesses at the 2010 FIFA World Cup seem similar or lower than in elite football players during the season. ${ }^{15}$

\section{CONCLUSION}

The incidence of match injuries during the 2010 FIFA World Cup was significantly lower than in three proceeding World Cups, but the proportion of non-contact injuries has increased. This might be a result of more regard to injury prevention in training, less foul play and stricter refereeing. Contact with another player was the most frequent cause of match and training injuries. Therefore, tackling skills and fair play need to be improved to prevent injuries. Illnesses were a minor problem, and most were infections of the respiratory or the digestive system. Their prevention should thus focus on the common modes of transmission and the environmental conditions.

Acknowledgements The authors appreciate the cooperation of all team physicians who gave of their time to collect the data for this project: Dr Mohamed Bouglali (Algeria), Dr Cristiano Eirale (Algeria), Dr Hakim Chalabi (Algeria), Dr Donato Villani (Argentina), Dr Peter Brukner (Australia), Dr Jose Runco (Brazil), Dr Serafim Borges (Brazil), Dr Guillaume Atchou (Cameroon), Dr Carlos Montes (Chile), Dr Mats Brjesson (Côte D'lvoire), Dr Soren Kaalund (Denmark), Dr lan Beasley (UK), Dr Alain Simon (France), Professor Tim Meyer (Germany), Dr Percy Annan (Ghana), Dr Harry Christopoulos (Greece), Dr Raul Medina (Honduras), Dr Luca Gatteschi (Italy), Dr Kuniaki Shimizu (Japan), Dr Ri Haknchol (Korea DPR), Dr Song Jun Seob (Korean Republic), Dr Radames Gaxiola (Mexico), Dr Gert-Jan Goudswaard (The Netherlands), Dr Celeste Geertsema (New Zealand), Dr Paul Onyeudo (Nigeria), Dr Osvaldo Pangrazio (Paraguay), Dr Manuel Aguilar (Paraguay), Dr Aldo Martinez (Paraguay), Dr Jose Henrique Jones (Portugal), Dr Miodrag Mladenovic (Serbia), Professor Viliam Fischer (Slovakia), Dr Matjaz Vogrin (Slovenia), Dr Ephraim Nematswerani (South Africa), Dr Oscar Luis Celada (Spain), Dr Juan Cota (Spain), Dr Roland Grossen (Switzerland), Dr Alberto Pan Montans (Uruguay), Dr Bert Mandelbaum (USA). The authors also express their gratitude to the FIFA medical officers: Dr Raúl Madero (Argentina), Professor Hosny Abdelrahman Ahmed (Egypt), Dr Terence Babwah (Trinidad and Tobago), Dato Dr Gurcharan Singh (Malaysia), Dr Tony Edwards (New Zealand), Dr Masoud Al-Riyami (Oman), Dr Carlos Palavicini (Costa Rica), Dr Yacine Zerguini (Algeria), and the administrative staff Dr Katharina

\section{What is already known on this topic}

- The incidence of match injuries was 2.7 per match in the 2002 FIFA World Cup and 2.3 in the 2006 FIFA World Cup.

- Most match injuries are caused by contact with another player.

- Frequent types of match injuries are thigh strains and ankle sprains.

\section{What this study adds}

- The incidence of match injuries constantly decreased from the 2002 FIFA World Cup to 2006 and further in 2010 (2.0 injuries per match; $95 \% \mathrm{Cl} 1.7$ to 2.3 ).

- Training injuries are frequent during the competition period, and $40 \%$ were incurred due to contact with another player.

- Illnesses were mainly infections of the respiratory or the digestive system. Most illnesses did not result in absence from training or match, and the expected duration of a time-loss illness was on average 1.8 days. 
Grimm (FIFA), Anja König (FIFA) and Sonja Schlumpf (FIFA). The authors gratefully acknowledge FIFA for their continued support of the injury surveillance project.

Funding This study was funded by Fédération Internationale de Football Association (FIFA), Zurich, Switzerland.

\section{Competing interests None.}

Ethics approval This study was conducted with the approval of the Research Ethics Committee of the Faculty of Health Sciences, University of Cape Town (ref. no. REC 159/2009)

Provenance and peer review Not commissioned; externally peer reviewed.

\section{REFERENCES}

1. Junge A, Dvorak J, Graf-Baumann T, et al. Football injuries during FIFA tournaments and the Olympic Games, 1998-2001: development and implementation of an injury-reporting system. Am J Sports Med 2004;32(1 Suppl):80S-9S

2. Dvorak J, Junge A, Grimm K, et al. Medical report from the 2006 FIFA World Cup Germany. Br J Sports Med 2007:41:578-81.

3. Junge A, Dvorak J, Graf-Baumann T. Football injuries during the World Cup 2002. Am J Sports Med 2004;32(1 Suppl):23S-7S.

4. Hägglund $\mathbf{M}$, Waldén M, Ekstrand J. UEFA injury study - an injury audit of European Championships 2006 to 2008. Br J Sports Med 2009;43:483-9.

5. Junge $\mathbf{A}$, Langevoort $\mathrm{G}$, Pipe $A$, et al. Injuries in team sport tournaments during the 2004 Olympic Games. Am J Sports Med 2006;34:565-76.

6. Langevoort G, Myklebust G, Dvorak J, et al. Handball injuries during major international tournaments. Scand J Med Sci Sports 2007;17:400-7.

7. Waldén $\mathbf{M}$, Hägglund $M$, Ekstrand J. Football injuries during European Championships 2004-2005. Knee Surg Sports Traumatol Arthrosc 2007:15:1155-62.
8. Yoon YS, Chai M, Shin DW. Football injuries at Asian tournaments. Am J Sports Med 2004; 32:36S-42S

9. Alonso JM, Junge A, Renström P, et al. Sports injuries surveillance during the 2007 IAAF World Athletics Championships. Clin J Sport Med 2009:19:26-32.

10. Junge A, Engebretsen L, Alonso JM, et al. Injury surveillance in multi-sport events: the International Olympic Committee approach. Br J Sports Med 2008;42:413-21.

11. Junge A, Engebretsen L, Mountjoy ML, et al. Sports injuries during the Summer Olympic Games 2008. Am J Sports Med 2009:37:2165-72.

12. Alonso JM, Tscholl PM, Engebretsen L, et al. Occurrence of injuries and illnesses during the 2009 IAAF World Athletics Championships. Br J Sports Med 2010;44:1100-5

13. Engebretsen L, Steffen K, Alonso JM, et al. Sports injuries and illnesses during the Winter Olympic Games 2010. Br J Sports Med 2010;44:772-80.

14. Mountjoy M, Junge A, Alonso JM, et al. Sports injuries and illnesses in the 2009 FINA World Championships (Aquatics). Br J Sports Med 2010;44:522-7.

15. Orhant $\mathbf{E}$, Carling $\mathrm{C}, \mathrm{Cox} \mathrm{A}$. A three-year prospective study of illness in professional soccer players. Res Sports Med 2010;18:199-204.

16. Fuller CW, Ekstrand J, Junge A, et al. Consensus statement on injury definitions and data collection procedures in studies of football (soccer) injuries. Clin J Sport Med 2006;16:97-106

17. Ekstrand J, Waldén $M$, Hägglund $M$. A congested football calendar and the wellbeing of players: correlation between match exposure of European footballers before the World Cup 2002 and their injuries and performances during that World Cup. Br J Sports Med 2004;38:493-7.

18. Soligard T, Myklebust G, Steffen K, et al. Comprehensive warm-up programme to prevent injuries in young female footballers: cluster randomised controlled trial. BMJ 2008;337:a2469. 